\title{
Mechanical and surface properties of low-density polyethylene film modified by photo-oxidation
}

\author{
Balasubramanian Suresh ${ }^{1,2}$, Sundaram Maruthamuthu ${ }^{1}$, Murugasamy Kannan ${ }^{3}$ and Angannan Chandramohan ${ }^{4}$ \\ Mechanical and surface properties are considered important in governing the physical strength of polymers. A commercially \\ available oxo-biodegradable polymer additive, which has induced surface and mechanical property changes during \\ photo-oxidation in low-density polyethylene (LDPE) films, has been studied. LDPE films containing the oxo-biodegradable \\ additive were irradiated with ultraviolet (UV)-B lamps at $30 \pm 1{ }^{\circ} \mathrm{C}$ for an extended time period. The changes manifested on the \\ polymer surface and in the mechanical properties were studied with respect to surface wettability, surface morphology using \\ scanning electron microscope, surface topology by atomic force microscopy, functional groups by Fourier transformed infrared \\ spectroscopy, absorbance spectra by UV-visible spectroscopy and elongation at break and tensile strength through mechanical \\ testing. The increase in the wettability and surface-free energy of the irradiated samples was attributed to the formation of \\ hydrophilic groups on the polymer surface by photo-oxidation, which occurs by the exposure of PE to UV irradiation in the \\ presence of air. The degree of reduction in the mechanical strength and surface property modifications in our study are \\ appreciable through the use of an oxo-biodegradable additive added to LDPE film samples.
} Polymer Journal (2011) 43, 398-406; doi:10.1038/pj.2010.147; published online 26 January 2011

Keywords: AFM; FT-IR; LDPE; oxo-biodegradable additive; photo-oxidation

\section{INTRODUCTION}

The application of polyolefins in various fields is influenced by their high thermal resistance, high tensile strength, high resistance to chemical deformations and low manufacturing cost. Polyolefin materials are designed according to their use as (1) durable materials (such as those used in aeronautical devices, construction materials, coatings and containers) and (2) short duration materials (for example, disposable bags, agricultural mulches, horticultural pots and so on). ${ }^{1}$ At this stage, the need to control plastic litter has become the primary concern of environment pollution control agencies. In a metropolitan area such as Chennai in India, about 3400 tons of plastic waste is generated every day, of which $35-40$ tons consist of plastic bags. ${ }^{2}$ Polyethylene is relatively inert because of its hydrophobic chains and high molecular weight. From earlier studies, it is evident that polyethylene biodegrades $<0.5 \%$ in 100 years and $\sim 1 \%$ if preexposed to sunlight for about 2 years. ${ }^{3}$ Low-density polyethylene (LDPE) is widely used in a variety of applications, and the accumulation of plastic waste in municipal solid waste systems creates many problems in (handling) their disposal. Because of its inert nature, plastic waste cannot be easily degraded by soil microbes and remains intact for many years. Previous exposure of PE materials to ultraviolet (UV) rays promotes polymer degradation ${ }^{4}$ by sunlight (naturally from the environment).
Many of the commercially available oxo-biodegradable additives help the degradation of polyethylene in the presence of sunlight. ${ }^{5}$ Oxo-biodegradable additives contain specific transition metals $(\mathrm{Mn}$, $\mathrm{Fe}$ and $\mathrm{Co}$ ) that function as pro-oxidants. ${ }^{6}$ These compounds function as catalysts in speeding up the normal reactions of oxidative degradation, with the overall reaction rate increased by several orders of magnitude. The products of the catalyzed oxidative degradation of plastics are precisely the same as those for conventional plastics because, other than the small amount of additive present, these plastics are indeed conventional plastics. ${ }^{6}$

Organometallic complexes are added as pro-oxidants, which in turn accelerate the process of natural weathering. ${ }^{7}$ Many researchers have used transition metals in their research, especially $\mathrm{Mn}, \mathrm{Fe}$ and $\mathrm{Co}$, which function as catalysts and generate initiation radicals during the photo-oxidation of polymers; in addition, transition metals are used in most commercial photodegradable pro-oxidant additives. ${ }^{8-10}$ The stearates of $\mathrm{Fe}^{3+}, \mathrm{Mn}^{2+11}$ and $\mathrm{Co}^{2+8},{ }^{2}$ and iron ${ }^{6}$ or metallic compounds such as cobalt stearate, cobalt palmitate cobalt laurate ${ }^{8}$ and titanium (VI) dioxide, ${ }^{12}$ can function as good pro-oxidants. The oxidative process involves (1) the formation of hydroperoxide and (2) the decomposition of these peroxides. Such oxidative reactions are initiated only when hydrogen is removed by a photoreaction (Scheme 1).

\footnotetext{
${ }^{1}$ Microbial-Corrosion Laboratory, Central Electrochemical Research Institute, Karaikudi, India; ${ }^{2}$ Department of Microbiology, Shri Nehru Maha Vidyalaya College of Arts and Science, Coimbatore, India; ${ }^{3}$ Department of Polymer Engineering, Amrita Vishwa Vidyapeetham University, Coimbatore, India and ${ }^{4}$ Department of Chemistry, Sri Ramakrishna Mission Vidyalaya College of Arts and Science, Coimbatore, India

Correspondence: Professor B Suresh, Department of Microbiology, Shri Nehru Maha Vidyalaya College of Arts and Science, Coimbatore, Tamil Nadu 641021, India. E-mail: sureshbalasubramanian77@gmail.com
}

Received 30 August 2010; revised 10 November 2010; accepted 22 November 2010; published online 26 January 2011 


$$
\begin{gathered}
\text { UV } \\
\text { Initiator } \rightarrow \quad R_{i}^{*} \\
R_{\mathrm{i}}^{*}+\mathrm{O}_{2} \rightarrow \quad R_{i} \mathrm{OO}^{*} \\
R_{i} \mathrm{OO}^{*}+\mathrm{R}-\mathrm{H} \rightarrow R_{i} \mathrm{OOH}+\mathrm{R}^{*} \\
(\mathrm{R}-\mathrm{H}=\text { Polyethylene, } \mathrm{Ri}=\text { alkyl group })
\end{gathered}
$$

Scheme 1 Catalyst residues as sources of radical generation.

Transient metal irons are typically added in the form of stearates or other organic ligand complexes as catalysts to generate initiation radicals. The free radicals formed in polyolefin react with oxygen to form peroxyl radicals, which can abstract a proton from some other labile positions and thereby form hydroperoxides and new radical sites. They introduce the functional groups and substances capable of promoting the formation of free radical precursor moieties (for example, hydroperoxides) by photophysical and thermal decomposition in order to induce cleavage of macromolecular polymer chains. ${ }^{13,14}$ The incorporation of transition metal compounds as photosensitizers and pro-oxidants was performed in order to enhance the oxidation of polyethylene exposed to light and temperature through the generation of free radicals reacting with molecular oxygen to produce peroxides and hydroperoxides. ${ }^{8,14,15}$ They eventually decompose in the presence of heat, light and metallic ions, leading to the formation of ketones and olefins. As a result, main chain scission and crosslinking are the major consequences of photo-oxidation of polyolefins. ${ }^{16}$

Polymerization catalysts such as transition metals (Ti) may remain in polyolefin at 2-100 p.p.m., depending on the composition and catalyst efficiency. For example, $\mathrm{TiO}_{2}$ is a well-known photosensitizer for polyolefin degradation and absorbs at $480 \mathrm{~nm}$. Photosensitization involves the formation of highly reactive species, including atomic oxygen, $\bullet \mathrm{OH}, \bullet \mathrm{OOH}$ and $\mathrm{O}_{2}{ }_{2}{ }^{13}$

The extent and rate of free radical oxidation of polyolefins are also affected by structural parameters such as chain defects and branching, with the latter being representative of relatively weak links susceptible to oxygen uptake to give hydroperoxides and bond cleavage. ${ }^{10}$ Abiotic reactions, initialized by the photo-oxidation of $\mathrm{PE}$, introduce oxygen in the form of carbonyl groups. ${ }^{17}$ This reaction is followed by microbial utilization of carboxylic groups by microorganisms, which release two carbon chain fragments that are further used in either the catabolic or the anabolic cycle in biotic environments. ${ }^{7}$ Photooxidation leads to the formation of carbonyl groups on the surface of $\mathrm{PE}$ and increases its hydrophilicity and surface energy, causing embrittlement. ${ }^{18}$ Oxo-biodegradable additives also contain antioxidants that prevent oxidative degradation during storage and use of the plastic product. ${ }^{11}$ Antioxidants function by 'deactivating' the free radicals that cause degradation and are routinely used in plastics. ${ }^{5,11}$ Product lifetime (shelf life+service life) is controlled by the antioxidant level, and the rate of degradation after disposal is controlled by the amount and nature of the catalyst used.

This research was undertaken to find the surface modification and change in mechanical properties catalyzed by commercially available oxo-biodegradable additives at various concentrations upon exposure to UV irradiation. Recently, their extended study has helped to explain the possibility of adherence of soil microflora on PE surfaces leading to biodegradation. During photodegradation, a broad spectrum of compounds such as esters, ketones and alcohols can also be formed. ${ }^{9}$
Table 1 Component characteristics of LDPE blown film samples used in UV irradiation tests

\begin{tabular}{lccc}
\hline Sample & Film thickness $(\mu \mathrm{m})$ & Oxo-biodegeradable & Polyethylene (\%) \\
\hline Code & Additive (\%) & - & \\
PE & $50 \pm 01$ & 10 & 100 \\
BPE10 & $50 \pm 01$ & 20 & 090 \\
BPE20 & $50 \pm 01$ & 080 \\
\hline
\end{tabular}

Abbreviations: LDPE, low-density polyethylene; PE, polyethylene; UV, ultraviolet.

Sunlight photolytic degradation or photo-oxidation occurs only when photoinitiators absorb wavelengths of the solar spectrum on earth $(>290 \mathrm{~nm})$. The described pro-oxidant treatment should simulate several months' exposure of the material to outdoor conditions. $^{12}$

This study was carried out to better monitor the increase in wettability, surface-free energy and surface roughness of modified LDPE films upon the introduction of hydrophilic groups on the polymer surface by photo-oxidation. This study aimed to investigate the surface and mechanical changes in LDPE film induced by photooxidation as influenced by a commercially available oxo-biodegradable additive.

\section{EXPERIMENTAL PROCEDURE}

\section{Materials}

Commercial-grade LDPE (24FSO40) was used for the preparation of polyethylene films. The melt flow index of the polymer was 1 . The commercially available oxo-biodegradable additive ('Biodegradable Masterbatch') containing the pro-oxidant additive cobalt (III) stearate $(0.3 \% \mathrm{w} / \mathrm{w})$, supplied by $\mathrm{K} \mathrm{K}$ Polycolor India (Chennai, India), was incorporated at varying ratios into pristine LDPE to prepare modified LDPE films.

\section{Preparation of biodegradable PE film}

Thin films $(50 \pm 01 \mu \mathrm{m})$ were prepared by mixing varying amounts of oxobiodegradable additive with LDPE in a film-blowing machine using an extruder (Gurusharan Polymer Make) with a $40 \mathrm{~mm}$ screw with an L/D ratio of 26:1 attached to a film-blowing die. A spiral die with a diameter of $10 \mathrm{~cm}$ and a die gap of $0.5 \mathrm{~mm}$ was used for this purpose. Films of uniform thickness were prepared using a constant nip roller and a processing speed of 35 r.p.m. under constant blowing. The temperature in the barrel zones was maintained at $125^{\circ} \mathrm{C}$ (feed zone) and $135^{\circ} \mathrm{C}$ (compression zone), and that of the die section was maintained at $150^{\circ} \mathrm{C}$ (die zone). The films were prepared as flat tubes with a bubble size of $150 \mathrm{~mm}$ in diameter.

Pristine LDPE films were designated as PE, and films containing oxobiodegradable additive were designated as BPE, followed by a numerical suffix indicating the amount of additive added. LDPE films containing 10 and $20 \%$ 'Biodegradable Masterbatch' were designated as BPE10 and BPE20, respectively, as shown in Table 1.

\section{Characterization techniques}

Photodegradation procedure. Films were irradiated with a 40-W UV-B lamp generating energy between 280 and $350 \mathrm{~nm}$, with a maximum $\left(\lambda_{\max }\right)$ at $313 \mathrm{~nm}$ in air at room temperature $\left(30 \pm 1^{\circ} \mathrm{C}\right)$ on open racks positioned $5 \mathrm{~cm}$ from the lamp. ${ }^{19}$ Exposures were conducted uninterrupted, $24 \mathrm{~h}$ per day, and the samples were recovered at different time intervals for up to 49 days.

Contact angle and surface energy. The wettability of the film surfaces submitted to UV irradiation was determined by contact angle measurements taken on samples using an OCA 20 video-based contact angle meter attached with a camera. The wetting liquid used was Millipore-grade distilled water (liquid 
surface tension $\left.\left(\gamma_{l}\right)=72.8 \mathrm{~mJ} \mathrm{~m}^{-2}\right)$. The value recorded was the average of five samples for each experiment.

Surface energy was calculated using the equation of state, Schultz Method-2, and Data Physics SCA20 software (Version 2.01).

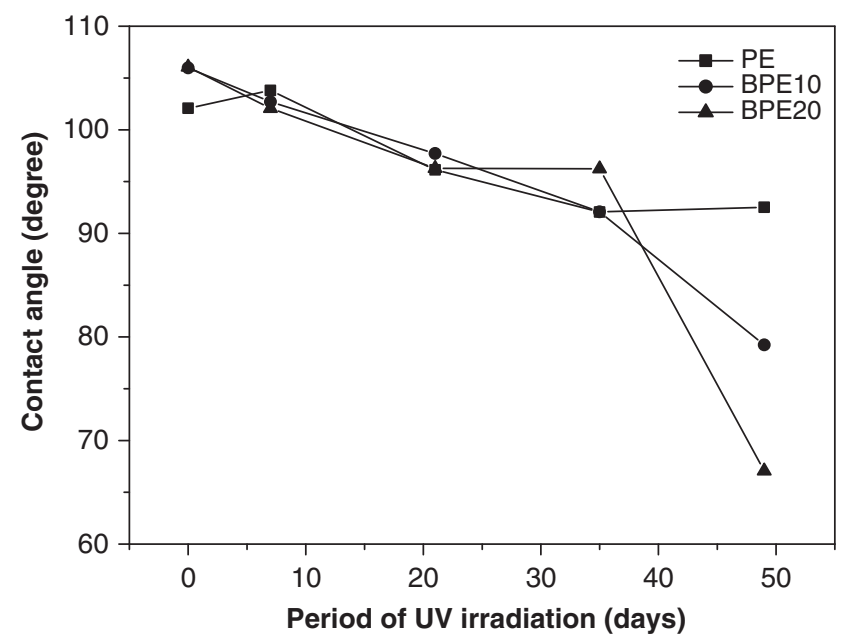

Figure 1 Variation in contact angle of ultraviolet (UV)-treated polyethylene (PE) and BPE films as a function of exposure time.

a

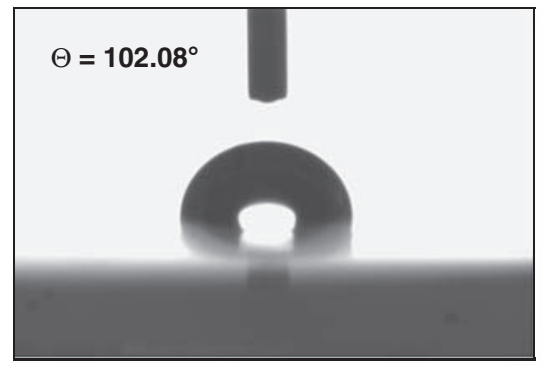

b

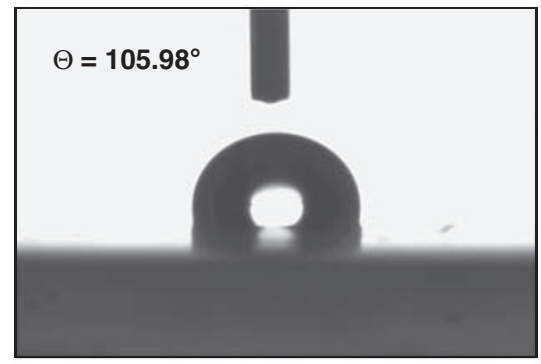

c

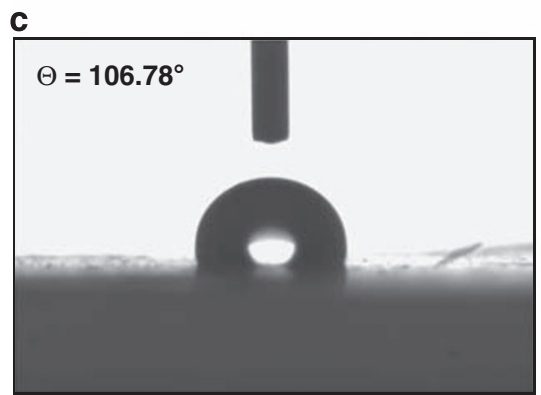

The adhesion work $\left(W_{\text {adh }}\right)$, a quantity related to surface wettability, was calculated using the following formula: ${ }^{20}$

$$
W_{\text {adh }}=\gamma_{l}(1+\cos \theta)
$$

where $\gamma_{l}$ and $\theta$ are the surface energy of the testing liquid and contact angle of LDPE, respectively.

Morphological analysis. Changes in surface morphology because of UV irradiation were investigated by scanning electron microscope (SEM; JEOL Model JSM-6390LV) using a voltage of $15 \mathrm{kV}$. Photomicrographs were taken at a 5000-fold uniform magnification, and the surface topography of the films was analyzed by atomic force microscopy (AFM; Solver P 47 PRO, Zelenograd, Moscow, Russia) under semi-contact mode and normal laboratory air atmosphere at a scan rate of $0.5 \mathrm{~Hz}$, using a single-crystal antimony-doped silicon probe to evaluate the change in surface topography because of UV irradiation.

Table 2 Influence of UV irradiation on work of adhesion of PE, BPE10 and BPE20

\begin{tabular}{lccccr}
\hline Sample & O day & 7 days & 21 days & 35 days & 49 days \\
\hline PE & 57.58 & 55.47 & 65.08 & 70.18 & 69.60 \\
BPE10 & 52.78 & 56.85 & 63.04 & 70.18 & 95.00 \\
BPE20 & 51.58 & 57.65 & 64.86 & 64.93 & 101.11 \\
\hline
\end{tabular}

Abbreviations: PE, polyethylene; UV, ultraviolet.

\section{a1}

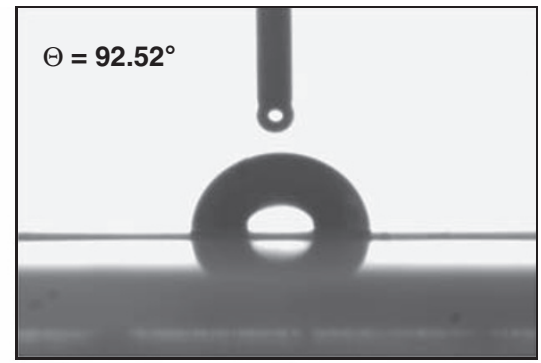

b1

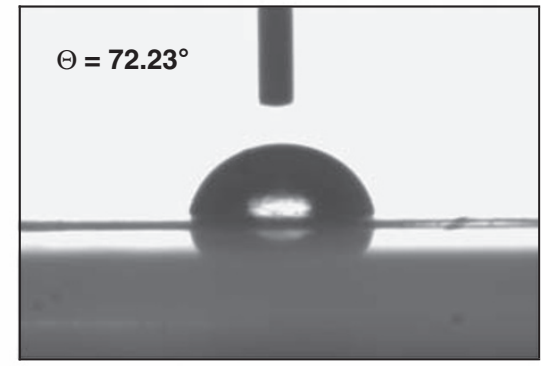

c1

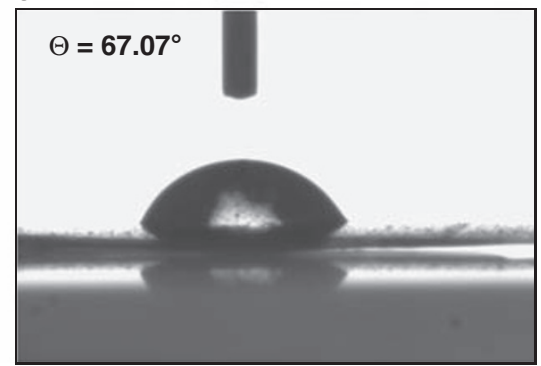

Figure 2 Comparative photographs of (a) untreated polyethylene (PE), (b) untreated BPE10 and (c) untreated BPE20 film with (a1) 49-day ultraviolet (UV)-irradiated PE, (b1) 49-day UV-irradiated BPE10 and (c1) 49-day UV-irradiated BPE20 film showing changes in contact angle. 
Fourier transformed infrared spectroscopy. The structural changes in LDPE films upon exposure were investigated using Fourier transformed infrared (FT-IR) spectroscopy. FT-IR spectra were recorded using a Thermo Nicolet, Avatar 370 spectrophotometer (Thermo Nicolet, Madison, WI, USA) in the spectral range of $4000-400 \mathrm{~cm}^{-1}$.

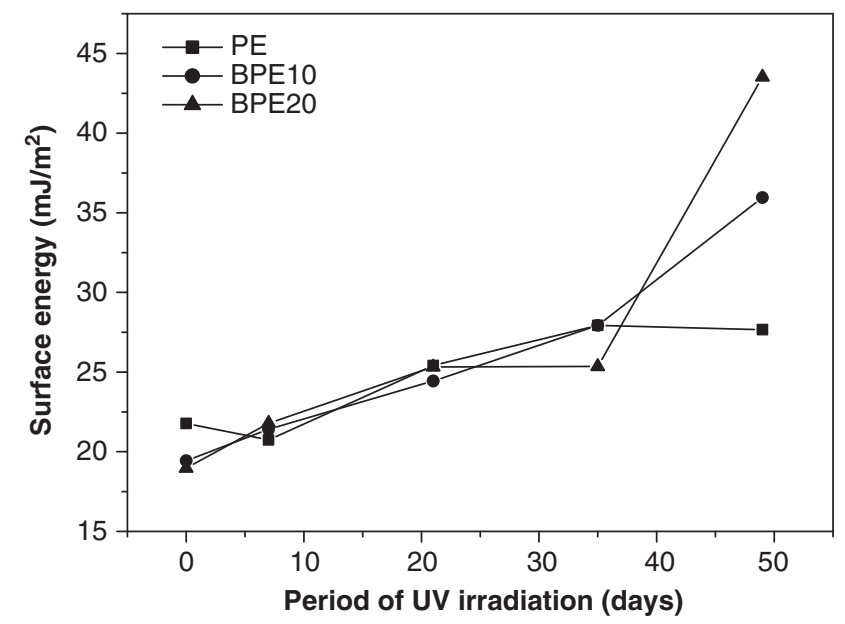

Figure 3 Surface energy variation profile of ultraviolet (UV)-treated polyethylene (PE) and BPE films as a function of exposure time.
UV-visible-near infrared spectroscopy. Changes in absorption spectra characteristic of pristine polyethylene and its blends before and after 49 days of irradiation were determined using a JASCO V-570 UV/visible spectrophotometer (JASCO, Tokyo, Japan) in the spectral range of $190-2500 \mathrm{~nm}$.

Mechanical strength test. Tensile tests were conducted on LDPE films according to ASTM 882 using an INSTRON machine (INSTRON, Norwood, MA, USA). Films of $100 \mathrm{~mm}$ length and $25 \mathrm{~mm}$ width were created and subjected to a cross-head speed of $100 \mathrm{~mm} \mathrm{~min}^{-1}$. The tests were conducted in an airconditioned environment at $21{ }^{\circ} \mathrm{C}$ and a relative humidity of $65 \%$. The value reported is the average of five samples for each experiment.

\section{RESULTS AND DISCUSSION}

The photodegradation of PE samples promoted by the oxo-biodegradable additive was measured by observing the wettability. There was a marked decrease in the contact angle with an increase in surface energy because of the introduction of carbonyl groups. The surface roughening of the polymer was evident in AFM images. The change in mechanical properties was monitored through the reduction in break at elongation and loss of tensile strength during photodegradation. When the irradiation period exceeded 49 days, the BPE20 sample became brittle and more fragile because of irradiation-induced photooxidation in the presence of a pro-oxidant in the oxo-biodegradable
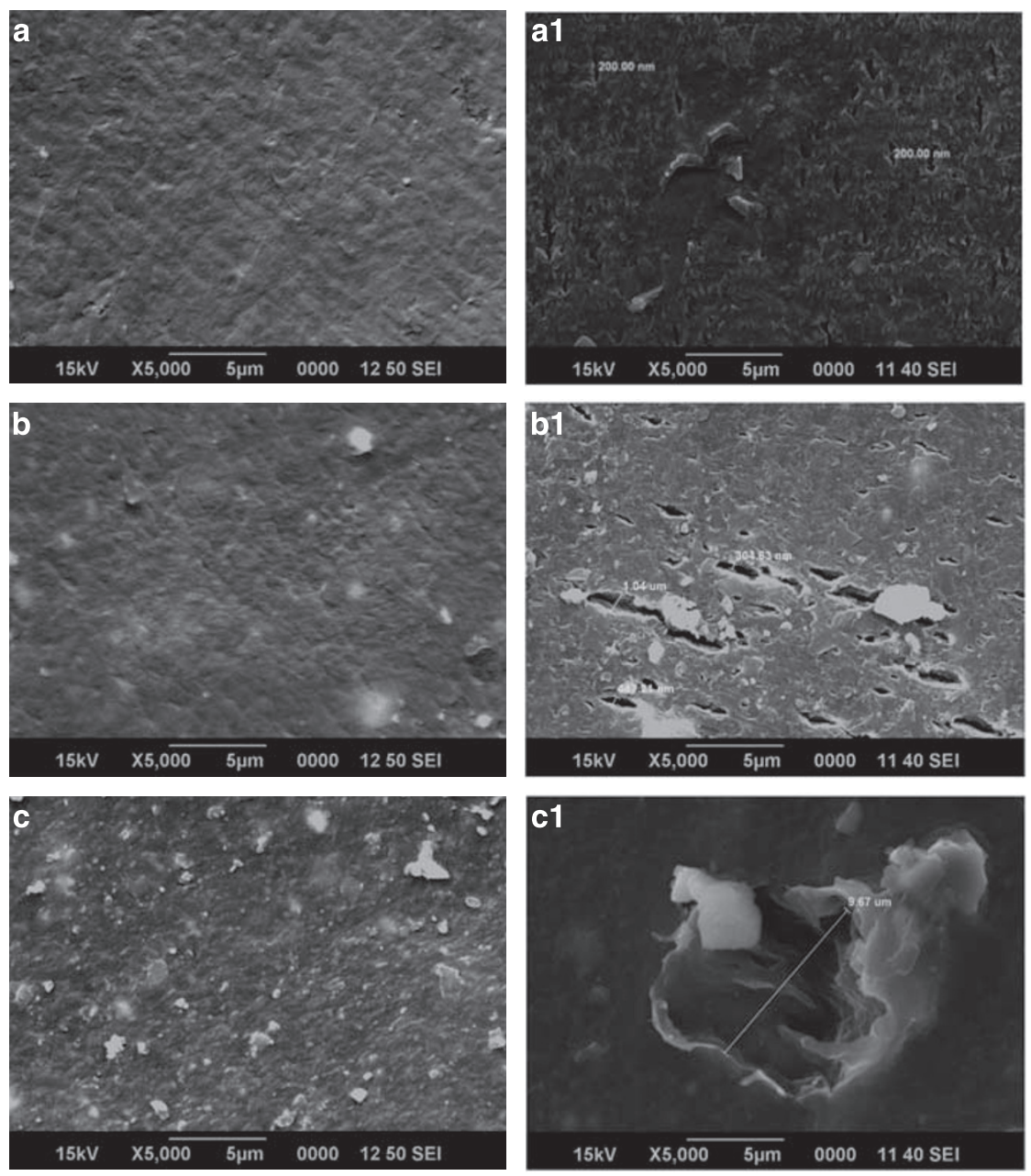

Figure 4 Comparative scanning electron microscope micrographs showing surface morphology of (a) untreated polyethylene (PE), (b) untreated BPE10 and (c) untreated BPE20 film with (a1) 49-day ultraviolet (UV)-irradiated PE, (b1) 49-day UV-irradiated BPE10 and (c1) 49-day UV-irradiated BPE20 films. 


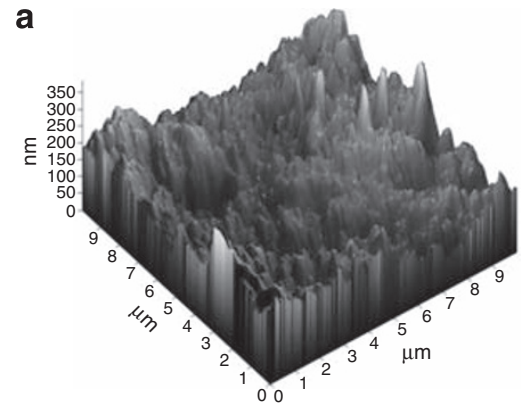

a1
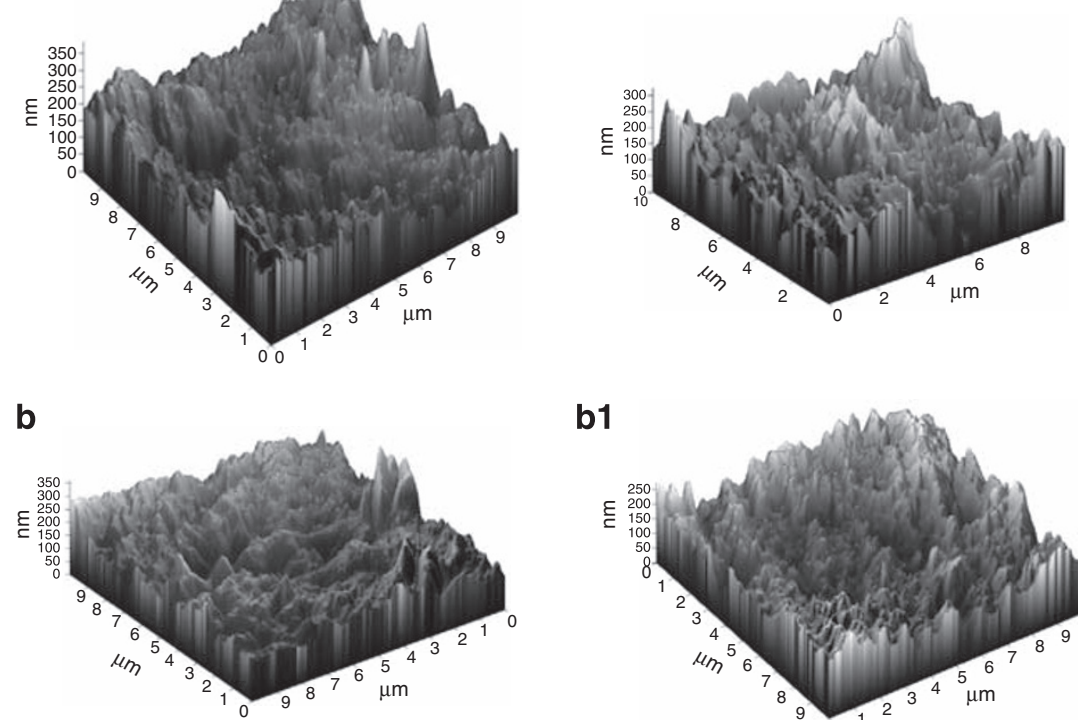

b1
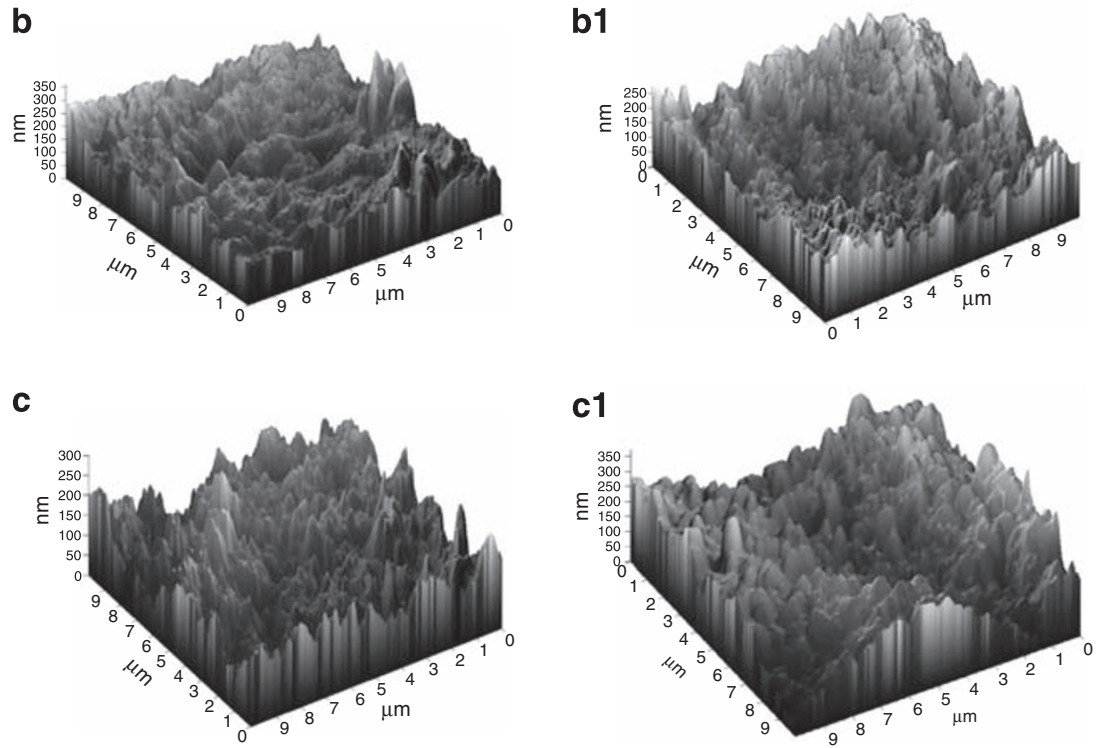

Figure 5 Comparative atomic force microscopy images showing surface topography of (a) untreated polyethylene (PE), (b) untreated BPE10 and (c) untreated BPE20 film with (a1) 49-day ultraviolet (UV)-irradiated PE, (b1) 49-day UV-irradiated BPE10 and (c1) 49-day UV-irradiated BPE20 films.

additive. Thus, this study was limited to 49 days of irradiation, and the photo-oxidation was monitored by various techniques.

\section{Photo-aging of a PE film sample containing pro-oxidant}

The photo-oxidation propensity of PE samples containing an oxobiodegradable additive, as induced by UV irradiation, was assayed using a UV-B lamp in air at room temperature. ${ }^{19}$ The tube has been shown to emulate solar wavelengths in the range below $360 \mathrm{~nm}$. Exposure of the films for more than 49 days made the BPE20 film more brittle and highly fragile; thus, the values were difficult to generate after 49 days.

Surface wettability: contact angle and surface energy measurements The extents of hydrophilic modification of UV-irradiated PE and BPE samples were investigated by contact angle measurements. Figure 1 shows the variation in the contact angle of the PE and BPE samples at different time intervals.

The contact angles of untreated PE, BPE10 and BPE20 films were $102.08^{\circ}, 105.98^{\circ}$ and $106.78^{\circ}$, respectively. After 49 days of UV treatment, the samples showed a marked decrease in contact angle to $92.52^{\circ}, 72.23^{\circ}$ and $67.07^{\circ}$ for PE, BPE10 and BPE20 films, respectively. The decrease in the contact angle of BPE20, which was more than that in the BPE 10 and PE films after UV irradiation under the same conditions, suggests that the increased concentration of additive may enhance the surface changes in LDPE films. After 49 days, the films became impossible to measure because of a complete disintegration of the BPE20 films.

The concentration of additive governing the reduction in the contact angles of PE samples was as follows: BPE20 $>$ BPE10 $>$ PE in terms of the acceleration of photodegradation (Figure 2). The decrease in contact angle produced the formation of hydrophilic groups on irradiated PE and BPE film surfaces. Upon the absorption of energy in the form of light, the components present in the pro-oxidant additive form free radicals. These species can combine with oxygen from air to generate polar groups, such as $-\mathrm{OH}, \mathrm{C}=\mathrm{O}, \mathrm{COOH}$ and $\mathrm{COO}-$, on the main chain of the polymer matrix. This leads to chain session in LDPE, which alters the hydrophobic nature of the surface. ${ }^{21}$ This phenomenon was relatively slower in PE films without a pro-oxidant additive.

The $W_{\text {adh }}$ of pristine LDPE and LDPE with a pro-oxidant additiveadded LDPE is presented in Table 2. $W_{\text {adh }}$ was calculated from contact angle measurements with respect to water. These measurements showed that the irradiated PE and BPE film sample values increased with irradiation time and concentration of the additive. There was a rise in the $W_{\text {adh }}$ value from $57.58,52.78$ and 51.58 to $69.60,95.00$ and 101.11 in PE, BPE10 and BPE20 films, respectively. The increment in $W_{\text {adh }}$ was suggested to have been due to the formation of new functional groups. 

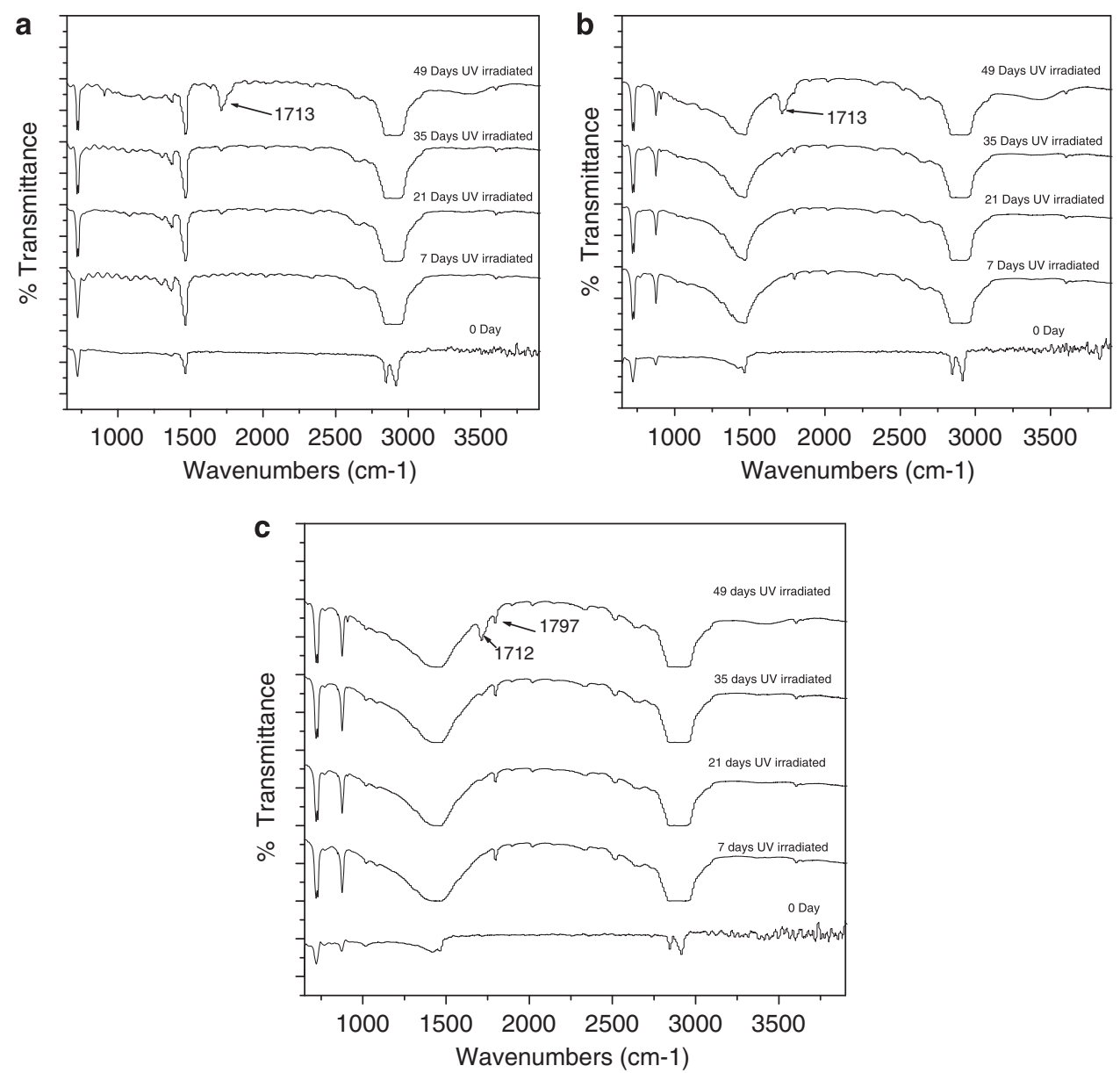

Figure 6 Effect of irradiation time on the Fourier transformed infrared spectra of (a) polyethylene, (b) BPE10 and (c) BPE20 films. UV, ultraviolet.

Figure 3 illustrates the variation in the surface energy of PE and BPE surfaces as a function of irradiation time and concentration of additive in LDPE. The surface energies of untreated PE, BPE10 and BPE20 films were $21.78,19.44$ and $18.97 \mathrm{~mJ} \mathrm{~m}^{-2}$, respectively. After irradiation, the surface energy increased with respect to time and concentration of additive in LDPE. Finally, on the 49th day of irradiation, the PE, BPE10 and BPE20 film samples showed increases in surface energy of $27.66,35.96$ and $43.52 \mathrm{~mJ} \mathrm{~m}^{-2}$, respectively. It was also revealed that under the same conditions (Figure 3 ), as the concentration of pro-oxidant additive increases, the surface energy also increases over time. This is mainly due to the formation of polar groups, such as $-\mathrm{OH}$, $\mathrm{C}=\mathrm{O}, \mathrm{COOH}$ and $\mathrm{COO}-$, in the polymer. The surface roughness is one of the important factors influencing the contact angle value. Wenzel $^{22}$ was the first to discover the influence of surface roughness on contact angle. He reported that a decrease in surface roughness produces an increase in contact angle. Hence, the surface energy is expected to increase for rougher surfaces because of a higher effective area, thereby increasing the hydrophilicity of the material. ${ }^{22}$

\section{Surface morphological and topographical analysis: SEM and AFM results}

The surface modifications in morphology of untreated PE, BPE10 and BPE20 films were measured by SEM analysis. Figure 4 shows an SEM micrograph of untreated PE, BPE10 and BPE20 films. Figures $4 a-c$ shows the surface morphology to be smooth, without any cracks and defects. Figure $4 \mathrm{a} 1$ shows the formation of smaller cracks $(200 \mathrm{~nm}$ in size) and surface peeling in PE without additive. Figures $4 \mathrm{~b} 1$ and $\mathrm{cl}$ are micrographs of BPE10 and BPE20 samples at 49 days of UV treatment. They show an increase in the size of cracks and grooves with an increase in the concentration of the pro-oxidant additive. In Figure $4 \mathrm{~b}$, the sample BPE10 film shows cracks measuring about 304-1000 nm in diameter. However, the extent of damage was much more pronounced in the sample shown in Figure 4c, which contained $20 \%$ additive; BPE20 shows a large groove measuring $9.6 \mu \mathrm{m}$ in diameter, and the deepening of the pit is more evident. Thus, the micrographs shed light on the acceleration of PE deterioration with additive concentration in the presence of oxygen. ${ }^{4,19}$ The increased crack size makes the polymer more brittle as the concentration of the pro-oxidant additive increases. The concentration of pro-oxidant additive influences the surface modification and facilitates surface cracking after 49 days of irradiation.

The semicontact mode AFM images (Figure 5) revealed an increase in surface roughness in all three samples after irradiation. Before irradiation, the surface roughness of the PE sample (Figure 5a) was $33.50 \mathrm{~nm}$, which increased after 49 days of irradiation in pristine PE (Figure 5a1) to $34.02 \mathrm{~nm}$. Samples BPE10 and BPE20 showed a marked increase in surface roughness from 33.65 and $33.65 \mathrm{~nm}$ to 35.31 and $46.54 \mathrm{~nm}$, respectively. This result was evidenced by the larger number of peak-like structures found in BPE20 than in the other two samples. The results reflect the influence of increased additive concentration in accelerating the process of LDPE backbone deterioration during photo-oxidation. 


\section{FT-IR analysis}

Structural changes upon irradiation were investigated by recording the FT-IR spectra of films with varying concentrations of additive and pristine polyethylene (before and after irradiation). Figure 6 shows the FT-IR spectra of samples as a function of irradiation time. The most significant changes in the IR absorption spectra were in the carbonyl $\left(1785-1700 \mathrm{~cm}^{-1}\right)$ peak. An increase in the intensity of the absorption band around $1713 \mathrm{~cm}^{-1}$, which can be assigned to the $\mathrm{C}=\mathrm{O}$ stretch of the saturated aliphatic ketocarbonyl group, was observed after 21 days of irradiation. ${ }^{11}$ In pristine PE, the carbonyl bond is a result of the overlap of various stretching vibration bands, including those of aldehydes and/or esters and carboxylic acid groups. ${ }^{23}$ The FT-IR spectrum of PE is shown in Figure 6a before and after irradiation for 49 days. It is evident that the saturated aliphatic ketone $\left(1713 \mathrm{~cm}^{-1}\right)$ peak is due to the progressive degradation of the PE chain caused by 49 days of photodegradation. ${ }^{8}$ The FT-IR spectra of BPE10 in Figure 6b shows the introduction of ketocarbonyl functional groups $\left(1713 \mathrm{~cm}^{-1}\right)$ after 21 days of irradiation; the intensity increases with the irradiation period for up to 49 days, and the simultaneous broadening of the band indicates the presence of more than one oxidation product. $^{24}$ In Figure $6 c$, the FT-IR spectrum of 20BPE indicates the formation of saturated aliphatic ketocarbonyl functional groups upon irradiation. The near regions of n-alkane and the secondary nitroalkane formation overlap one another causing a broadening of the peak; $\mathrm{CH}_{3}$ deformation was deemed responsible for $\mathrm{C}-\mathrm{H}$ scissoring. ${ }^{24}$ The intensity of $\mathrm{C}=\mathrm{O}$ stretching at the ketocarbonyl functional group $\left(1712 \mathrm{~cm}^{-1}\right)$ peak increases with prolonged irradiation. ${ }^{24,25}$

This spectral analysis provided evidence for the photo-oxidation of the PE films, and the oxidation of the material was evidenced by the formation of carbonyl groups. ${ }^{17,26-30}$

\section{UV-visible spectral analysis}

The changes in the UV-visible absorption spectra of pristine and prooxidant-added PE are shown in Figure 7. Each final absorption spectrum is that of the non-irradiated and irradiated PE, BPE10 and BPE20 films. The PE film after irradiation does not show much of an increase in its absorption coefficient within the region of $200-350 \mathrm{~nm}$, where the BPE10 and BPE20 samples showed an increase in absorption. The intensity of such alterations increased with radiation time. Irradiated samples tend to exhibit a red shift in the wavelength of the UV cutoff. It is worth noting that, for these polyethylene samples, absorbance does not increase for pristine PE, but the absorbance increases with varying concentrations of additive in PE. In addition, the absorbance is apparently more affected by irradiation at wavelengths of $200-350 \mathrm{~nm}$. The changes observed could be due to unsaturations and the presence of carbonyl and hydroxyl compounds. ${ }^{31,32}$ Irradiation of LDPE produces a combination of degradation and crosslinking, accompanied by the formation of unsaturated products. If the irradiation is carried out in the presence of air, in most cases carbonyl and hydroxyl compounds are formed. ${ }^{33}$

\section{Mechanical properties}

The changes in the tensile strength and elongation at break because of UV irradiation are shown in Figures 8 and 9. The pristine PE sample showed a slight reduction in tensile strength of $14 \mathrm{MPa}$ from 16.5 MPa. The samples BPE10 and BPE20 showed a gradual increase and were slow in losing their tensile strength. In our experiment, we found that the deterioration was visually evident in the sample BPE20 in which the pro-oxidant additive was present at a higher concentration. The rapid loss in the mechanical strength of the polymer
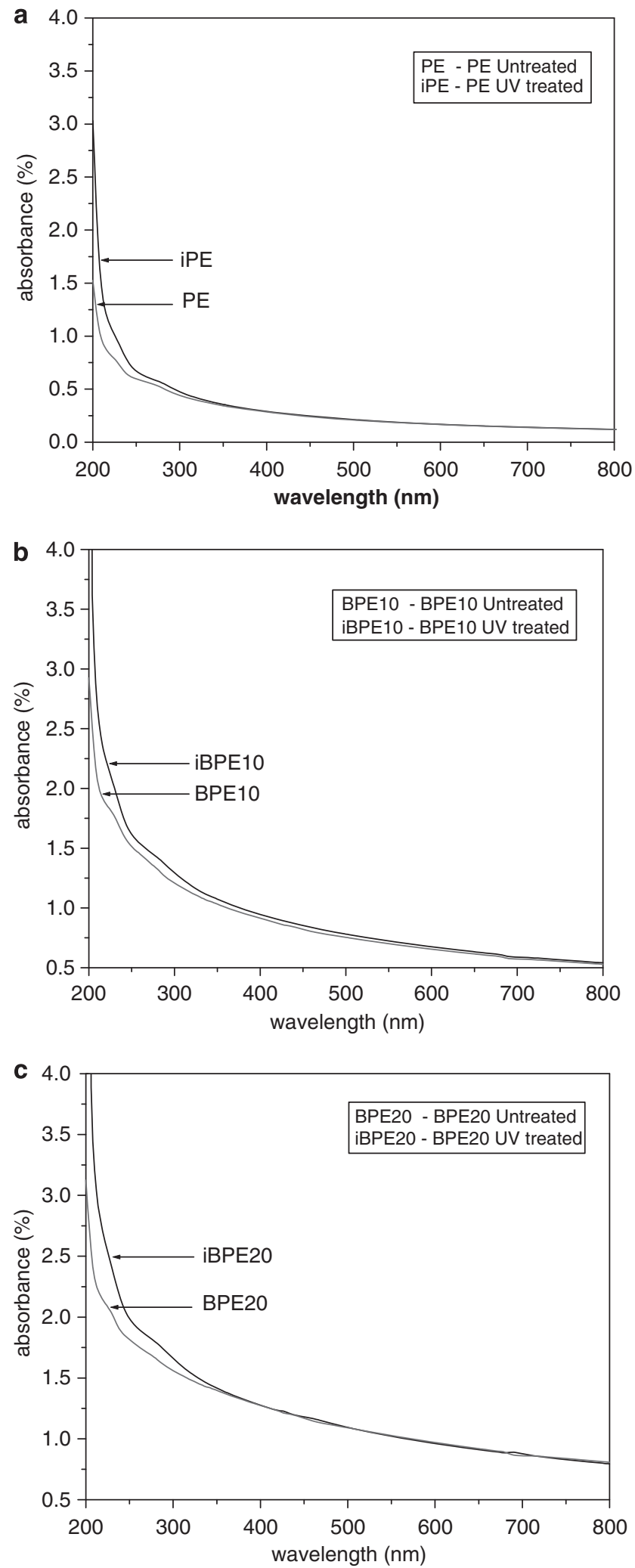

Figure 7 Effect of irradiation time on the ultraviolet (UV)-visible absorption spectra of (a) polyethylene (PE), (b) BPE10 and (c) BPE20 films.

containing the additive after 49 days was due to the absorption of energy in the form of light; moreover, it has been shown that the pro-oxidant catalyzes chain session by forming free radicals. ${ }^{25-27}$ The 


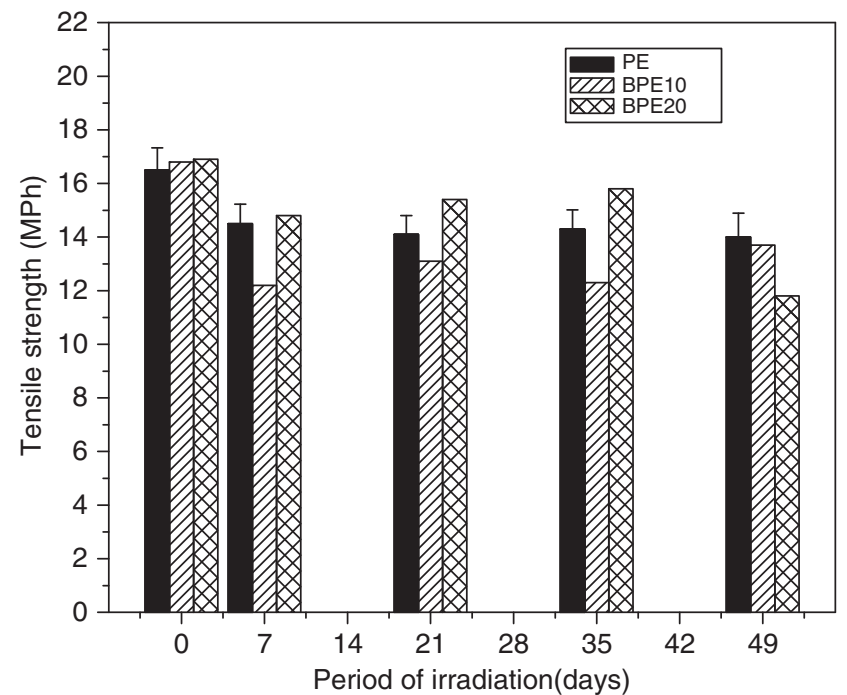

Figure $\mathbf{8}$ Variation in tensile strength with ultraviolet irradiation. PE, polyethylene.

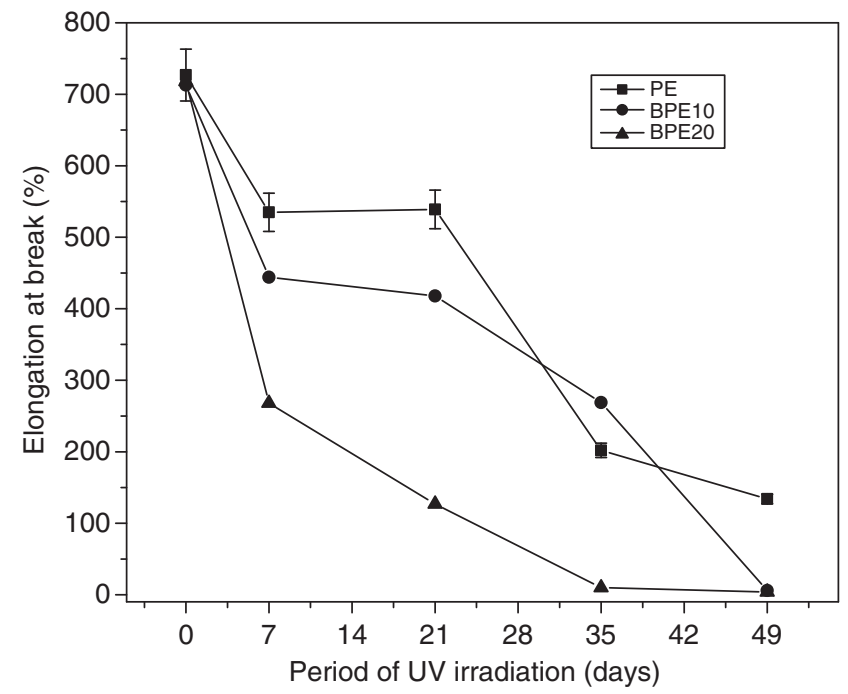

Figure 9 Percentage elongation with ultraviolet (UV) irradiation. PE, polyethylene.

tensile strength was reduced from 16.8 and 16.9 to 13.7 and $11.8 \mathrm{MPa}$ in samples BPE10 and BPE20, respectively.

The pristine $\mathrm{PE}$, even after 49 days of irradiation, retained a minimum elongation at break (Figure 9), retaining its elasticity. The sample film that did not contain the pro-oxidants also became fragile and fragmented, although at lower rates, with some cracking and fragmentation. ${ }^{6}$ However, the pro-oxidant additive had a vital role in accelerating the polymer chain session during photo-oxidation, causing the samples BPE10 and BPE20 to lose their elongation at break rapidly. ${ }^{14}$ In BPE20, this produces an immediate change in its mechanical properties by inducing brittleness, as the concentration of pro-oxidant additive increases with time beyond 49 days of irradiation and may suggest that circulated oxygen in air could provoke cracking, ${ }^{24}$ thereby rendering the film useless for practical applications.

\section{CONCLUSIONS}

Wettability changes in LDPE films introduce hydrophilic groups that modify their hydrophobic nature, which are evidenced by a decrease in contact angle and a sharp rise in surface energy. SEM micrographs have shown the formation of larger holes on the surfaces of LDPE films containing oxo-biodegradable additive, and the increase in the surface roughness of such films has been evidenced by AFM imaging; this increase in surface roughness reduces the mechanical strength of the polymer. The incorporated additive may contain photosensitizers that catalyze photo-oxidation. The ability of the metal stearate to catalyze the degradation process has been reported to arise from its ability to intramolecularly cleave radicals, which can abstract hydrogen from the polymer chain and generate free radicals. The mechanical properties of LDPE films with incorporated additive were found to become more fragile after 49 days of UV irradiation compared with those of the pristine LDPE film. Surface changes and photo-oxidative degradation are influenced by the concentration of the additive in LDPE, and follows the order BPE20 $>$ BPE10 $>$ PE. UV irradiation in the presence of additive influences polyethylene surface modification by the incorporation of oxygen in the polymer chain and the formation of various carboxylic groups inducing hydrophilicity.

From the results, it can be concluded that

- the change in contact angles and surface energy in the modified polymers is due to the formation of hydrophilic groups;

- the micro pores and cracks produced and the increase in surface roughness in the modified polymer (pro-oxidant added) alter the mechanical properties of the film (irregularities in the surface may form nucleation sites for cracks);

- the increase in wettability and decrease in physical strength of the modified polymer are directly proportional to the irradiation time, the percentage of additive incorporated and the increase in the uptake of oxygen.

The modified polymers can be used in the packaging industry because they reduce the accumulation of polyethylene in soil, which further facilitates microbial attachment on the polymer surface and aids biodegradation.

\section{ACKNOWLEDGEMENTS}

We thank The Director, CECRI, Karaikudi, for his kind permission. We also thank M/S Sri Lakshmi Narayana Plastics, Coimbatore, for providing the pristine polyethylene and blended polyethylene films and for their helpful discussions. Appreciation is also extended to Sophisticated Test \& Instrumentation Centre (STIC), Cochin University of Science and Technology, Cochin, Kerala, for providing analytical support.

1 Koutny, M., Amato, P., Muchova, M., Ruzicka, J. \& Delort, A. M. Soil bacterial strains able to grow on the surface of oxidized polyethylene film containing prooxident additives. Int. Biodeterior. Biodegrad. 63, 354-357 (2009).

2 The Times of India Vol 2, Issue 197, p 2 (2009).

3 Khabbaz, F. \& Albertsson, A. C. Rapid test methods for analyzing degradable polyolefins with a prooxident system. J. Appl. Polym. Sci. 79, 2309-2316 (2001).

4 Karzmarek, H., Kamiñska, A., Światek, M. \& Sanyal, S. Photoinitiated degradation of polystyrene in the presence of low-molecular organic compounds. Eur. Polym. J. 36, 1167-1173 (2000).

5 Pfaender, R. How will additives shape the future of plastics? Polym. Degrad. Stab. 91, 2249-2256 (2006).

6 Ojeda, T. F. M., Dalmolin, E., Forte, M. M. C., Jacques, R. J. S., Bento, F. M. \& Camargo, F. A. Abiotic and biotic degradation of oxo-biodegradable polyethylenes. Polym. Degrad. Stab. 94, 965-970 (2009).

7 Koutny, M., Lemaire, J. \& Delort, A. M. Biodegradation of polyethylene films with prooxident additives. Chemosphere 64, 1243-1252 (2006). 
8 Roy, P. K., Surekha, P., Rajagopal, C. \& Choudhary, V. Effect of cobalt carboxylates on the photo-oxidative degradation of low density polyethylene. Part -I. Polym. Degrad. Stab. 91, 1980-1988 (2006).

9 Osawa, Z., Kurisu, N., Nagashima, K. \& Nankano, K. The effect of transition metal stearate on the photodegradation of polyethylene. J. Appl. Polym. Sci. 23, 3583-3590 (1979).

10 Lee, B., Pometto Anthony, L., Fratzke, A., Theodore, B. \& Bailey, J. R. Biodegradation of degradable plastic polyethylene by Phanerochaete and Streptomyces species. Appl. Environ. Microbiol. 57, 678-685 (1991).

11 Qureshi, F. S., Amin, M. B., Maadhah, A. G. \& Hamid, S. H. Weather induced degradation of linear low density polyethylene: mechanical properties. J. Polym. Eng. 9, 67-84 (1990).

12 Kemp, T. J. \& McIntyre, R. A. Influence of transition metal-doped titanium (IV) dioxide on the photodegradation of polyethylene. Polym. Degrad. Stab. 91, 3020-3025 (2006)

13 Baljit, S. \& Sharma, N. Mechanistic implications of plastic degradation. Polym. Degrad. Stab. 93, 561-584 (2008).

14 Chiellini, E., Corti, A., Antone, S. D. \& Baciu, R. Oxo-biodegradable carbon backbone polymers - oxidative degradation of polyethylene under accelerated test conditions. Polym. Degrad. Stab. 91, 2739-2747 (2006).

15 Khabbaz, F., Albertsson, A.- C. \& Karlsson, S. Chemical and morphological changes of environmentally degradable poly(ethylene) exposed to thermo-oxidation. Polym. Degrad. Stab. 63, 127-138 (1999).

16 Erlandsson, B., Karlsson, S. \& Albertsson, A.- C. Themode of action of corn starch and a pro-oxidant system in LDPE: influence of thermooxidation and UV-irradiation on the molecular weight changes. Polym. Degrad. Stab. 55, 237-245 (1997).

17 Sudhakar, M., Trishul, A., Mukesh, Doble, Suresh Kumar, Syed Jahan, S., Inbakandan, D., Viduthalai, R. R., Umadevi, V. R., Sriyutha Murthy, P. \& Venkatesan, R. Biofouling and biodegradation of polyolefins in ocean waters. Polym. Degrad. Stab. 92, 17431752 (2007)

18 Jakubowicz, I. Evolution of degradability of biodegradable polyethylene. Polym. Degrad. Stab. 80, 39-43 (2003).

19 Roy, P. K., Surekha, P., Rajagopal, C., Raman, R. \& Choudhary, V. Study on the degradation of LDPE in presence of cobalt stearate and benzyl. J. Appl. Polym. Sci. 99, 236-243 (2006).

20 Navaneetha Pandiyaraj, K., Selvarajan, V., Deshmukh, R. R. \& Gao, C. Adhesive properties of polypropylene (PP) and polyethylene terephthalate (PET) film surfaces treated by DC glow discharge plasma. Vacuum 83, 332-339 (2008).
21 Bikaris, D., Prinos, J., Perrier, C. \& Panayiotou, C. Thermo analytical study on the effect of EAA and starch on the thermooxidative degradation of LDPE. Polym. Degrad. Stab. 57, 313-324 (1997).

22 Wenzel, R. N. Resistance of solid surfaces to wetting by water. Ind. Eng. Chem. 28, 988 (1936).

23 Valadez-Gonzalez, A., Cervantes-Uc, J. M. \& Veleva, L. Mineral filler influence on the photo-oxidation of high density polyethylene: I. Accelerated UV chamber exposure test. Polym. Degrad. Stab. 63, 256-260 (1999).

24 Sudesh, S., Fernando, P. A., Christensen, T. A. \& Egerton, J. R. W. Carbon dioxide evolution and carbonyl group development during photodegradation of polyethylene and polypropylene. Polym. Degrad. Stab. 92, 2163-2172 (2007).

25 Allen, N. S., Paul, A., Egerton, T. A. \& White, J. R. Comparison of various thermal and photoageing conditions on the oxidation of titanium dioxide pigmented linear low density polyethylene films. Polym. Degrad. Stab. 52, 311-320 (1996).

26 Roy, P. K., Surekha, P., Rajagopal, C., Chatterjee, S. N. \& Choudhary, V. Studies on the photo-oxidative degradation of LDPE films in the presence of oxidised polyethylene. Polym. Degrad. Stab. 92, 1151-1160 (2007).

27 Saucedo, J.- E., Lucas, N., Bienaime, C., Belloy, C., Queneudec, M. \& Silvestre, F. Polymer biodegradation: mechanisms and estimation techniques. Chemosphere 73, 429-442 (2008).

28 Albertsson, A. C., Andersson, S. O. \& Karlsson, S. The mechanisms of biodegradation of polyethylene. Polym. Degrad. Stab. 18, 73-87 (1987).

$29 \mathrm{Ji}$-Dong, Gu. Biopolymers. Microbial deterioration of synthetic and biological polymers used in engineering and construction Vol. 10. 117 (Wiley-VCH GmbH \& Co, KgaA, 2003).

30 Koutny, M., Sancelme, M., Catherine Dain, C., Pichon, P., Delort, A. M. \& Lemaire, J. Acquired biodegradability of polyethylenes containing pro-oxidant additives. Polym. Degrad. Stab. 91, 1495-1503 (2006).

31 Kaczmarek, H., Oldak, D. \& Podgorski, A. Photochemical properties of polyethylene modified by low-molecular organic compounds. Polym. J. 35, 634-639 (2003).

32 Moura, E. A. B., Ortiz, A. V., Wiebeck, H., Paula, A. B. A., Silva, A. L. A. \& Silva, L. G. A. Effects of gamma radiation on commercial food packaging films-study of changes in UV/VIS spectra. Radiation. Phys. Chem. 71, 199-202 (2004).

33 Spinks, J. W. T. \& Woods, R. J. Introduction to Radiation Chemistry 3 ed, p 468 (Wiley, 1990). 